\title{
Compressive Strength and Microstructure of Modified Coffee Exocarp Cement-based Composites
}

\author{
Zehua Zhu, ${ }^{a}$ Cheng Cheng, ${ }^{\text {a,b }}$ Debin Zhu, ${ }^{\text {a,* }}$ Dewen Liu, ${ }^{\text {a }}$ and Yafei Zhang ${ }^{\text {a }}$ \\ Portland cement-based composites were prepared with coffee exocarp \\ (pretreated with water or $\mathrm{NaOH}$ ) via vacuum extraction technology. An \\ orthogonal test was adopted to analyze the influence of various factors on \\ mechanical properties of the composite. The morphology and composition \\ of the pretreated coffee exocarp and composites were analyzed via \\ environmental scanning electron microscopy and X-ray diffraction, \\ respectively. The results showed that the coffee exocarp content and \\ vacuum extraction time significantly affected the compressive strength. An \\ addition of $10 \%$ coffee exocarp had a slight negative effect on the \\ mechanical properties but enhanced the crack inhibition and overall \\ toughness of the composite. The scanning electron microscopy and X-ray \\ diffraction results showed that the composite containing coffee exocarp \\ pretreated with $4 \% \mathrm{NaOH}$ solution had the highest density and exhibited \\ the best properties due to mechanical interlocking between the coffee \\ exocarp and cement. After $28 \mathrm{~d}$ of curing, the composites exhibited a \\ maximum compressive strength of $15.72 \mathrm{MPa}$, a mass that was \\ approximately $37 \%$ less than that of ordinary Portland cement samples, \\ and a bulk density of $1.5 \mathrm{~g} / \mathrm{cm}^{3}$ to $1.6 \mathrm{~g} / \mathrm{cm}^{3}$. Hence, the produced \\ biocomposites could be used for low-load pavements, providing a new \\ type of economical building material.
}

Keywords: Coffee exocarp; Biocomposites; Microstructure analysis; Pretreatment; Crop residues

Contact information: a: School of Civil Engineering, Southwest Forestry University, Kunming 650224 PR China; $b$ : Wood Adhesives and Glued Products Key Laboratory of Yunnan Province, Kunming 650224 PR China; *Corresponding author: xnlydxzdb@sina.com

\section{INTRODUCTION}

As one of the three most popular beverages in the world, coffee is widely planted throughout the world. The largest coffee-growing province in China is Yunnan province. At present, large-scale coffee factories in Yunnan province generally use a water washing method to obtain coffee beans. The water washing method involves putting the coffee fruit into the degumming machine to remove the flesh. The beans are then soaked in water for 12 to $24 \mathrm{~h}$ and stirred regularly to remove the remaining pulp and pectin from the skin surface. After drying at $20{ }^{\circ} \mathrm{C}$ for 2 weeks, the exocarp and coffee beans are finally separated by a sheller. A large amount of processing waste is generated during coffee production every year; the production of 1 ton of coffee generates approximately 1 ton of pulp and 1 ton of exocarp waste. Under natural conditions, these valuable biomass resources cannot be effectively used, and thus, they are typically slowly degraded after being stacked or are directly burned. 
In recent years, there have been an increasing number of studies using crop residue fibers in building materials, many of which have been successfully developed and applied (Coutts 2005; Khorami and Ganjian 2011). This type of composite material has the same advantages as Portland cement; moreover, studies have shown that adding crop residue fibers to composite materials results in a lower density and greater toughness. Although plant fibers can be the base reinforcement of cement-based composite materials, this type of composite material still has two disadvantages. First, in the alkali environment of cement hydration, carbohydrate precipitates dissolve out of the fibers, which delays the coagulation and anticoagulation effects on cement and affects the interfacial bonding between the fibers and cement. Second, the plant fibers are mixed into the composite material, leading to the decreased homogenization and a degradation of mechanical performance (Savastano et al. 2003). Therefore, researchers have applied sodium hydroxide pretreatment to the biomass material and found that this method could effectively treat the waxy layer on the fiber surface. The surface becomes rough, which is beneficial to the interface adhesion and compatibility between the substrates (Fan et al. 2012). Meanwhile, by improving the preparation plan for reducing the size of the internal pores and studying the influence of plant fibers on the mechanical performance of composite materials, plant fibers can become an acceptable engineering building material (Xie et al. 2016).

Some scholars have added certain proportions of coffee grounds and sugarcane ash to a cement base to form a dense roadbed pavement material (Bekalo and Reinhardt 2010). Since coffee grounds have a particle size similar to sandy soil (Arulrajah et al. 2017), they can also be treated to replace certain building materials. However, the inclusion of coffee exocarp into building materials is rare. This study evaluated the feasibility of mixing coffee exocarp with ordinary Portland cement to manufacture composite materials. Since coffee exocarp has a wide range of stable sources and is renewable as well as degradable, this form of composite material would properly utilize biomass resources. Coffee exocarp is different from other biomass materials, and it is more conducive to the preparation of composite materials. Compared with other plant fibers, more pectin and fructose are removed, which can reduce the hindrance of saccharide to cement hydration. After a long drying time, the inner water content of coffee exocarp is small, which reduces the influence on the later preparation of composite materials. The strength and toughness of coffee exocarp are used to prepare cement-based composite materials, which are used for sidewalks with low bearing capacity or green roads in residential areas, making it a new alternative green construction material (Qiao et al. 2015).

In this study, to obtain favorable values of water/cement ratio, coffee exocarp content, sand content, and vacuum extraction process time, the mixing ratio was optimized through orthogonal tests. The coffee exocarp samples were subjected to different pretreatment processes, i.e., an aqueous solution treatment or sodium hydroxide solution treatments of different concentrations, before preparing the specimens, and the compressive strengths of the samples were measured. Environmental scanning electron microscopy (ESEM) and X-ray diffraction (XRD) were used to systematically characterize the interfacial bonding between the coffee exocarp and the composite and assess the elemental composition of the materials. Finally, the physical properties of the coffee exocarp composites, e.g., the bulk density, apparent porosity, water absorption, and walking comfort, were studied. 


\section{EXPERIMENTAL}

\section{Materials}

The coffee exocarp waste used in this study came from Arabica coffee grown locally in the Yunnan province. The coffee exocarp is the seed coat of the coffee bean. It has a certain toughness and rough texture, and the main components of the coffee exocarp are $47.7 \% \pm 1.57 \%$ cellulose, $29.4 \% \pm 1.08 \%$ lignins, $22.4 \% \pm 0.92 \%$ hemicelluloses, and $0.5 \% \pm 0.3 \%$ ash. The cellulose and lignin contents in coffee exocarp were higher than the cellulose and lignin contents in straw and rice husks but lower than those in hardwood. The hemicellulose content in coffee exocarp was similar to the hemicellulose content in straw and rice husks and higher than that in hardwood (Wang and Wu 2013; Xie et al. 2016). The ash content in coffee exocarp was lower than the ash contents in straw, rice husks, and hardwood. The coffee exocarp was crushed and passed through a 10 mesh sieve; the largesized fiber that was not sifted was used, and the length was $2 \mathrm{~mm}$ to $5 \mathrm{~mm}$ (Fig. 1).

Fig. 1. The coffee exocarp used in the experiment

The cement used in this paper was 42.5 ordinary Portland cement (OPC) produced by Kunming Cement Co., Ltd. (Kunming, China). The results of the chemical composition of the cement are shown in Table 1. The fine aggregate used in this study was graded river sand (with a fineness modulus of 2.6), which met the requirements of ASTM standard C33 (2003). The $\mathrm{NaOH}$ used in this study was a colorless transparent crystal with a volume density of $2.130 \mathrm{~g} / \mathrm{cm}^{3}$. Calcium chloride $\left(\mathrm{CaCl}_{2}\right)$ was used as the cement curing accelerator. The water used in this study was clean laboratory tap water with a $\mathrm{pH}$ of 6.6.

Table 1. Chemical Composition of OPC

\begin{tabular}{|c|c|c|c|c|c|c|c|}
\hline $\begin{array}{c}\text { Components } \\
\text { (wt.\%) }\end{array}$ & $\mathrm{SiO}_{2}$ & $\mathrm{Al}_{2} \mathrm{O}_{3}$ & $\mathrm{Fe}_{2} \mathrm{O}_{3}$ & $\mathrm{CaO}$ & $\mathrm{MgO}$ & $\mathrm{SO}_{3}$ & $\mathrm{Cl}$ \\
\hline OPC & 20.75 & 4.56 & 2.98 & 63.66 & 2.85 & 3.02 & 0.01 \\
\hline
\end{tabular}

\section{Pretreatment of the Coffee Exocarp}

In this study, to verify the effectiveness of the $\mathrm{NaOH}$ solution and aqueous solution pretreatments, the coffee exocarp was soaked in the aqueous solution and $1 \%, 2 \%, 3 \%$, $4 \%$, and $5 \% \mathrm{NaOH}$ solutions for $24 \mathrm{~h}$, and the mass loss was recorded at $6 \mathrm{~h}, 12 \mathrm{~h}, 24 \mathrm{~h}$, $48 \mathrm{~h}$, and $72 \mathrm{~h}$ after soaking. Then, the residual sodium hydroxide solution was washed off the coffee rind with water several times until the $\mathrm{pH}$ value was 7 . The pretreated coffee exocarp was placed in a ventilated place and dried to less than $0.5 \%$ moisture content so 
that the moisture content of the coffee exocarp would not affect the preparation of subsequent experiments.

\section{Experimental Design}

IBM SPSS Statistics 26.0 software was used to investigate the mechanical properties of the composite material and analyze the compressive strength of the composite material according to the influence of the coffee exocarp content, water/cement ratio, sand content, and vacuum extraction time. An $\mathrm{L}_{16}\left(4^{5}\right)$ orthogonal table was used in this study to find the optimal combination of parameters. The range method was used to analyze the orthogonal test. The greater the range was, the greater the impact on the compressive strength. Using this method, the optimal mixing ratio of the coffee exocarp composite could be determined.

Although the orthogonal test range analysis is an intuitive analysis, it cannot distinguish whether the differences in the experimental results at different factor levels are due to the different factor levels or to experimental errors. Therefore, analysis of variance (ANOVA) was used for further verification.

\section{Preparation of Composite Materials}

The coffee exocarp cement-based composite was prepared according to ASTM standard C109 (2005) (Torkaman et al. 2014). In the orthogonal experimental design, the contents of coffee exocarp, cement, and river sand were calculated by the weight percentage, and $2 \% \mathrm{CaCl}_{2}$ was added as an accelerator for the hydration process. The mixture was placed in a cement mortar mixer and stirred for 3 min at $1500 \mathrm{rpm}$ to evenly disperse the fibers in the slurry. Then, a $\mathrm{CaCl}_{2}$ solution (diluted with water) was added to the mixture and stirred for 3 min. Next, the mixture was quickly poured into a special mold (as shown in Fig. 2) and vibrated for 1 min to meet the compaction requirements. The upper surface of the mold was covered with an iron cover plate the same size as the mold, and the four sides of the cover plate were sealed with rubber to ensure the tightness of the mold during vacuum extraction. A plastic tube was placed into a metal sealing tube, and the metal sealing tube was connected to the suction hole and a circulating water-type vacuum pump with an extraction pressure of $0.5 \mathrm{MPa}$ (Soroushian et al. 2004; Xie et al. 2015). Vacuum extractions of the samples for different times were performed according to the test design. The dimensions of the molded test block were $150 \mathrm{~mm}^{3} \times 150 \mathrm{~mm}^{3} \times 150 \mathrm{~mm}^{3}$.

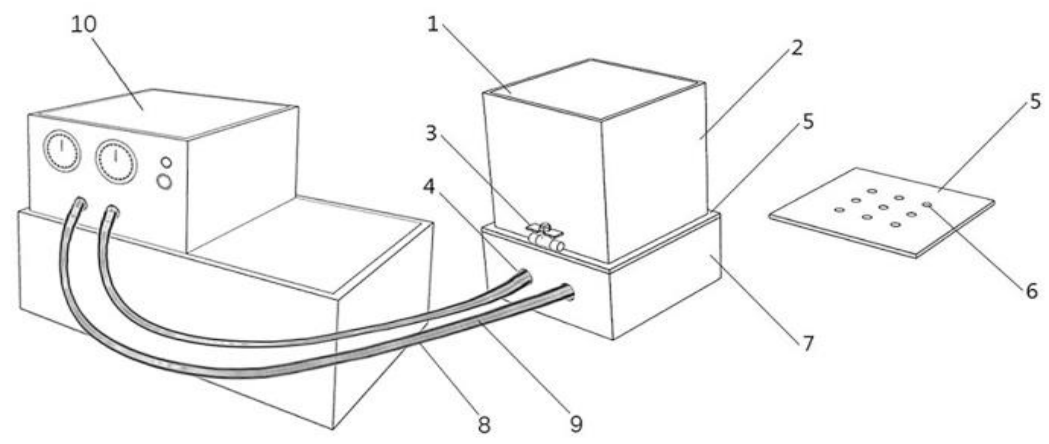

Fig. 2. Vacuum extraction process mold (1 - cover plate; 2 - molding and mold testing; 3 - bottom bolt; 4 - extraction hole; 5 - perforated division plate; 6 - drain hole; 7 - base; 8 - metal sealing tube; 9 - plastic pipe; and 10 - circulating water vacuum pump) 
After the unextracted sample was stored for $24 \mathrm{~h}$, the sample was demolded with a hydraulic stripper machine, and after the vacuum extraction process was completed, the sample was placed in a sealing bag. After the sample was stored at room temperature (20 ${ }^{\circ} \mathrm{C}$ ) for $1 \mathrm{~d}$, it was then moved to a location with a relative humidity greater than $90 \%$ until it reached the desired experimental age (the results are shown in Fig. 3).

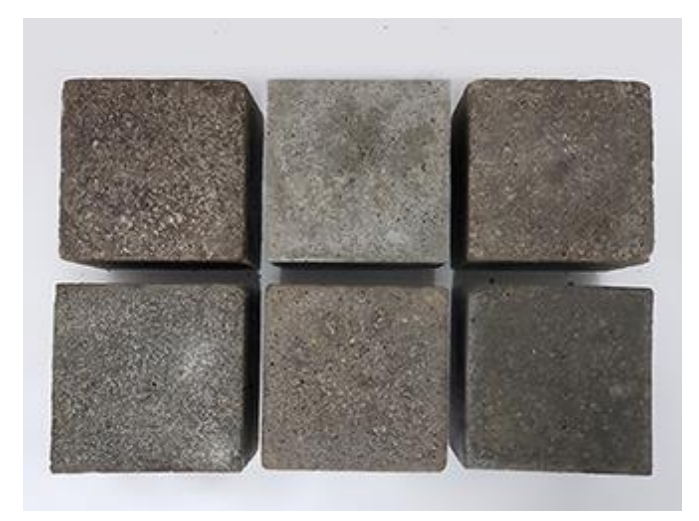

Fig. 3. Coffee exocarp composite material

\section{Performance Testing and Characterization of the Composite Materials}

The mechanical performance of each mixing ratio was calculated from the average of three identical samples. After the samples had been subjected to $28 \mathrm{~d}$ of standard curing, the samples were subjected to compression tests using a WA-100 electrohydraulic universal testing machine at a constant displacement rate of $10 \mathrm{~mm} / \mathrm{min}$, and the maximum load was recorded.

The composite material was characterized using an Ultima IV multifunctional horizontal X-ray diffractometer with a $\mathrm{CuK} \alpha$ radiation source, a wavelength of 0.15405 $\mathrm{nm}$, a working voltage of $40 \mathrm{kV}$, a working current of $30 \mathrm{~mA}$, a scanning angle range of $5^{\circ}$ to $80^{\circ}$, and a scanning speed of $1.2 \% \mathrm{~min}$. The hydration specimen was removed from storage and ground into a powder with a specific surface area of $300 \mathrm{~m} / \mathrm{kg}$ to $400 \mathrm{~m} / \mathrm{kg}$. Then, an appropriate amount of the specimen was placed in a square groove on a glass plate, flattened, and then placed in the diffractometer. By analyzing the diffraction curve, the elemental composition and chemical reactions that occurred in the material were determined.

An FEI Quanta 200 environmental scanning electron microscope was used to compare the two specimen groups. In the first group, the surface morphologies of the coffee exocarp were compared before and after treatments with a $4 \% \mathrm{NaOH}$ solution and aqueous solution. In the second group, the composite was mechanically pulverized into small pieces (less than $1 \mathrm{~cm}^{3}$ ). The specimens without mechanical imprinting were selected and immersed in anhydrous ethanol to terminate the hydration reaction and were then dried and plated with gold for observation via ESEM. Then, the micromorphology properties and bonding of the interface between the coffee exocarp and cement paste under different pretreatment methods were compared (Torres and Cubillas 2005).

The physical properties, e.g., bulk density, water absorption, and apparent porosity, of the composite materials were determined in accordance with ASTM standard C29 (2009). The physical properties were calculated from the mean values of six samples, and standard deviations were recorded. The test sample was immersed thoroughly into water and soaked at $25{ }^{\circ} \mathrm{C}$ for $24 \mathrm{~h}$ as per the requirement for the water absorption ratio. After 
using paper tissue to wipe off the surplus moisture on surface of the test sample, its water absorption ratio was calculated based on the added mass of the test sample in the immersion process. The samples were cured in the curing box for the corresponding days, then dried in the drying box until the weight was constant, weighed on a balance with sensitivity of \pm $0.001 \mathrm{~g}$. The bulk density of the sample is the ratio of mass to volume after drying. To evaluate whether walking on composite materials is more comfortable, an elastic test was used. Golf balls (GB) and steel balls (SB) were used and dropped freely from the height of $100 \mathrm{~cm}$ to the center of the specimen surface. The weight of the steel balls was $66.7 \mathrm{~g}$, and the diameter was $25.4 \mathrm{~mm}$. The rebound height after falling was recorded with a motion camera. The ratio of the rebound height to free falling height is the GB coefficient and SB coefficient (Whittle et al. 1994).

\section{RESULTS AND DISCUSSION}

\section{Optimum Compound Ratio}

Table 2 shows the orthogonal test results and their analysis, and Table 3 shows the ANOVA results.

Table 2. Results and Range Analysis of the Orthogonal Test

\begin{tabular}{|c|c|c|c|c|c|c|c|}
\hline $\begin{array}{c}\text { Test } \\
\text { Number }\end{array}$ & $\begin{array}{c}\text { Factor A } \\
\text { Coffee } \\
\text { Exocarp } \\
\text { Content(\%) }\end{array}$ & $\begin{array}{c}\text { Factor B } \\
\text { Water/Cement } \\
\text { Ratio }\end{array}$ & $\begin{array}{c}\text { Factor C } \\
\text { Sand } \\
\text { Content } \\
(\%)\end{array}$ & $\begin{array}{c}\text { Factor D } \\
\text { Vacuum } \\
\text { Extraction } \\
\text { Time (h) }\end{array}$ & $\begin{array}{c}\text { Null } \\
\text { Columns }\end{array}$ & $\begin{array}{c}\text { 28d } \\
\text { Compressive } \\
\text { Strength } \\
(\mathrm{MPa})\end{array}$ & $\begin{array}{c}\text { Dry } \\
\text { density } \\
\left(\mathrm{g} / \mathrm{cm}^{3}\right)\end{array}$ \\
\hline 1 & $1(5)$ & $1(0.3)$ & $1(0)$ & $1(2)$ & 1 & 7.90 & 1.39 \\
\hline 2 & 1 & $2(0.35)$ & $2(10)$ & $2(4)$ & 2 & 8.31 & 1.38 \\
\hline 3 & 1 & $3(0.4)$ & $3(20)$ & $3(6)$ & 3 & 8.49 & 1.40 \\
\hline 4 & 1 & $4(0.45)$ & $4(30)$ & $4(8)$ & 4 & 7.45 & 1.37 \\
\hline 5 & $2(10)$ & 1 & 2 & 3 & 4 & 7.98 & 1.36 \\
\hline 6 & 2 & 2 & 1 & 4 & 3 & 7.73 & 1.35 \\
\hline 7 & 2 & 3 & 4 & 1 & 2 & 8.46 & 1.39 \\
\hline 8 & 2 & 4 & 3 & 2 & 1 & 8.04 & 1.36 \\
\hline 9 & $3(15)$ & 1 & 3 & 4 & 2 & 6.58 & 1.31 \\
\hline 10 & 3 & 2 & 4 & 3 & 1 & 7.19 & 1.33 \\
\hline 11 & 3 & 3 & 1 & 2 & 4 & 7.37 & 1.32 \\
\hline 12 & 3 & 4 & 2 & 1 & 3 & 6.70 & 1.28 \\
\hline 13 & $4(20)$ & 1 & 4 & 2 & 3 & 5.84 & 1.25 \\
\hline 14 & 4 & 2 & 3 & 1 & 4 & 6.01 & 1.25 \\
\hline 15 & 4 & 3 & 2 & 4 & 1 & 5.66 & 1.20 \\
\hline 16 & 4 & 4 & 1 & 3 & 2 & 6.29 & 1.26 \\
\hline k1 & 8.04 & 7.08 & 7.32 & 7.27 & - & - & \\
\hline k2 & 8.05 & 7.31 & 7.16 & 7.39 & - & - & \\
\hline k3 & 6.96 & 7.50 & 7.28 & 7.49 & - & - & \\
\hline k4 & 5.95 & 7.12 & 7.24 & 6.86 & - & - & \\
\hline Range & 2.10 & 0.42 & 0.16 & 0.63 & - & - & \\
\hline & Influence Order & & & A D D B $>$ C & & \\
\hline & & & & A2:B3:C3:D3 & & \\
\hline
\end{tabular}


Table 3. Variance Analysis of Orthogonal Test

\begin{tabular}{|c|c|c|c|c|c|c|}
\hline $\begin{array}{c}\text { Sources of } \\
\text { Variance }\end{array}$ & $\begin{array}{c}\text { Deviation } \\
\text { Sum of } \\
\text { Squares }\end{array}$ & $\begin{array}{c}\text { Degrees of } \\
\text { Freedom }\end{array}$ & $\begin{array}{c}\text { Mean } \\
\text { Square }\end{array}$ & F Value & P Value & $\begin{array}{c}\text { Statistical } \\
\text { Significance }\end{array}$ \\
\hline Model & 13.583 & 12 & 1.132 & 24.814 & 0.011 & ${ }^{* *}$ \\
\hline A & 12.153 & 3 & 4.051 & 88.806 & 0.002 & ${ }^{* * *}$ \\
\hline B & 0.445 & 3 & 0.148 & 3.249 & 0.180 & - \\
\hline C & 0.056 & 3 & 0.019 & 0.410 & 0.758 & - \\
\hline D & 0.929 & 3 & 0.310 & 6.791 & 0.075 & ${ }^{*}$ \\
\hline Error & 0.137 & 3 & 0.046 & - & - & - \\
\hline Total & 13.720 & 15 & - & - & - & - \\
\hline \multicolumn{7}{|l}{} \\
\hline \multicolumn{7}{|l}{$\mathrm{R}^{2}=0.990$} \\
\hline
\end{tabular}

The analysis showed that the influence of factor A on the compressive strength of the composite was significant ( $p$-value was less than 0.01 ) and that the influence of factor $\mathrm{D}$ on the compressive strength of the composite was also significant ( $p$-value was less than 0.1 ). A larger $F$ value showed that the change of this factor will have a more significant impact on the compressive strength of the sample. Hence, the order of influence of the factors from high to low was A, D, B, and C. The analysis results of the two tests were consistent with these results.

In conclusion, the mean values of A2, B3, C3, and D3 were the highest among the mean values of each factor level. However, neither B nor $\mathrm{C}$ were significant ( $p$-value was greater than or equal to 0.1 ), and there was no significant difference between the levels. Therefore, the best levels of $\mathrm{B}$ and $\mathrm{C}$ could be selected in accordance with the specific situation. In consideration of the test and the theory, A2:B3:C3:D3 was determined to be the best combination. The compressive strength of the sample corresponding to this combination was the highest out of all of the tested composites.

The following conclusions can be drawn from the significance of orthogonal experiment factors:

(1) As the coffee exocarp dosage increased, the compressive strength of the composite material first increased and then decreased. Under these conditions, when the coffee exocarp dosage was $10 \%$, the compressive strength of the sample was the highest. When a small amount of coffee exocarp was used in the composite mixture, it was conducive to forming an interleaved stress structure. However, if the increase in the coffee exocarp dosage was too high, it would drastically affect the cementation of the cementing materials. Hence, adding an excessive amount of coffee exocarp was not conducive to forming a dense structure inside the composite materials.

(2) As the vacuum extraction time increased, the compressive strength of the composite materials containing coffee exocarp first increased and then decreased. The results showed that the sample could be directly demolded after the vacuum extraction process was finished. In contrast, the sample of the traditional cement mortar needed to be demolded with the help of the hydraulic stripper, which could only occur $24 \mathrm{~h}$ after the molding process. This indicated that the vacuum extraction process could not only promote cement setting and hardening but also strengthen the sample at an early stage. Under the precondition that the vacuum extraction process can satisfy the workability of the composite materials, this process helped remove excess water from the cement paste, which decreased the water/cement ratio to some extent (Zhang et al. 2011). Moreover, the vacuum extraction process also decreased the number of pores left inside the sample when 
the water was evaporated after hydration. As a result, the compressive strength was improved. However, when the vacuum extraction time was too long, too much water inside the sample was lost, which could negatively affect the compressive strength.

\section{Verification test}

Since there was no A2:B3:C3:D3 combination testing during the orthogonal test, a verification test was carried out to examine the reasonability of the selected best combination. The samples were prepared with $10 \%$ coffee exocarp, $20 \%$ sand, a 0.4 water to cement ratio, and a $6 \mathrm{~h}$ vacuum extraction time. The average compressive strength of three identical specimens was $8.87 \mathrm{MPa} \pm 0.78 \mathrm{MPa}$, which was higher than that of any other combinations.

\section{Effect of the Coffee Exocarp Pretreatment on the Composite Material}

Figure 4 shows that as the immersion time increased, the mass loss of the pretreated coffee exocarp gradually increased. At $0 \mathrm{~h}$ to $12 \mathrm{~h}$, the slope of the mass loss curve was large, which indicated that the mass loss was fast. At $24 \mathrm{~h}$, the loss gradually stabilized, which accounted for $96 \%$ of the total mass loss. When immersed for $24 \mathrm{~h}$ to $48 \mathrm{~h}$, the slope of the curve decreased, and the change in mass was subtle, i.e., the mass basically did not change after $48 \mathrm{~h}$. Figure 4 also shows the $\mathrm{NaOH}$ solution concentration and mass loss. When the immersion time was the same, the mass loss increased as the $\mathrm{NaOH}$ solution concentration increased, but when the solution concentration exceeded $4 \%$, the change range of the coffee exocarp mass loss curve decreased drastically and tended to be constant. Therefore, the selected pretreatment scheme for the coffee exocarp was $24 \mathrm{~h}$ of immersion in a $4 \% \mathrm{NaOH}$ solution.

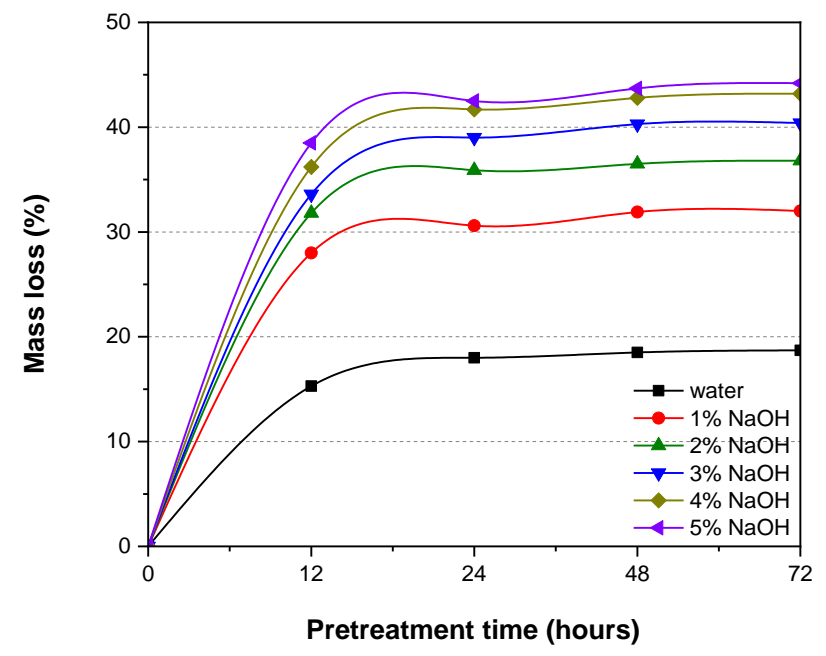

Fig. 4. Mass loss of coffee exocarp

The mass loss of the coffee exocarp pretreated with a $4 \% \mathrm{NaOH}$ solution was 2.5 times greater than the mass loss of the coffee exocarp pretreated with an aqueous solution. The reason for this difference was that coffee exocarp contains monosaccharides, oligosaccharides, and starch, which are soluble in water, whereas the alkali solution dissolved the above substances as well as completely dissolving the fructose and fatty acids, which removed most of the low-molecular-weight impurities found in the fibers. 
According to the experimental data, the correctness of the pretreatment of the coffee exocarp with an aqueous solution and $\mathrm{NaOH}$ solution was verified. Under the condition of A2:B3:C3:D3, different pretreated coffee exocarp samples were selected to prepare the samples. The samples prepared with untreated coffee exocarp were labeled $\mathrm{S} 1$, the samples prepared with coffee exocarp subjected to an aqueous solution treatment were labeled S2, and the samples prepared with coffee exocarp subjected to a $4 \% \mathrm{NaOH}$ solution treatment were labeled S3. A cement mortar sample was prepared by replacing the coffee exocarp with the same amount of sand, which was used as the standard group. The compressive strengths of the different samples were recorded at different curing ages, as shown in Fig. 5 .

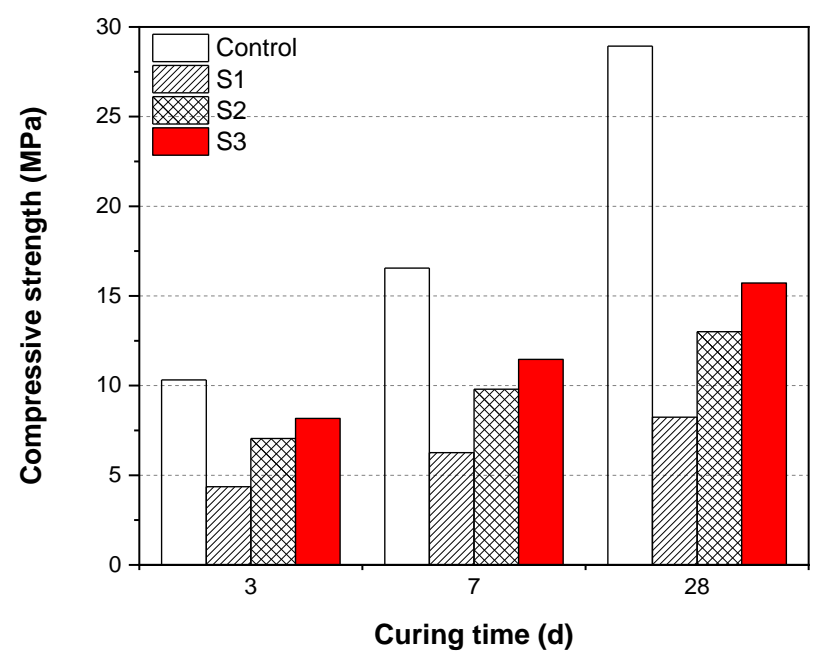

Fig. 5. Compressive strengths of samples at different curing times: S1 nontreatment; S2 water treatment; and S3 $4 \% \mathrm{NaOH}$ treatment

The data in Fig. 5 show that the early compressive strength of the three groups of composite materials (S1, S2, and S3) was low. As the curing time increased, the compressive strength of S1 changed slightly, whereas the compressive strengths of S2 and $\mathrm{S} 3$ showed considerable growth trends. After $7 \mathrm{~d}$ of curing, the compressive strength of S3 was $11.5 \mathrm{MPa}$, which was $17 \%$ higher than the compressive strength of S2 at the same curing age. After $28 \mathrm{~d}$ of curing, the growth of the compressive strengths of the samples tended to plateau, and the maximum compressive strength measured was $15.7 \mathrm{MPa}$ (for S3), which was $54.3 \%$ of the compressive strength of the cement mortar sample at the same curing age. When the mixing ratio and storage conditions were the same, a $4 \% \mathrm{NaOH}$ solution pretreatment had a greater impact on the compressive strength of the sample than an aqueous solution pretreatment; the compressive strength of the unprocessed sample was the lowest among the three groups (Song et al. 2015; Teixeira et al. 2020).

The cement hydration process led to the generation of an alkaline environment. The saccharide found in the coffee exocarp was gradually converted into saccharic acids. The saccharic acids reacted with the calcium ions generated through the cement hydration process to form a saccharic acid calcium shell, which hindered any further hydration of the cement. Since the mass loss of the coffee exocarp represented the precipitation mass of the extracted substances, the alkali-treated coffee exocarp exhibited the highest mass loss; therefore, its effect on the delayed setting and hardening of cement is the weakest (Garci 
Juenger and Jennings 2002). Moreover, the sample pretreated with alkali solution showed the maximum compressive strength, which indicated that the alkali treatment method reduced the impact of the plant fibers on the cement hydration process (Ataie et al. 2015). Additionally, the alkaline solution destroyed the wax layer found on the coffee exocarp, which led to a greater surface reactivity due to the exposed rough inner surface. Hence, the compatibility between the exposed coffee exocarp and the cement was improved via an alkali treatment.
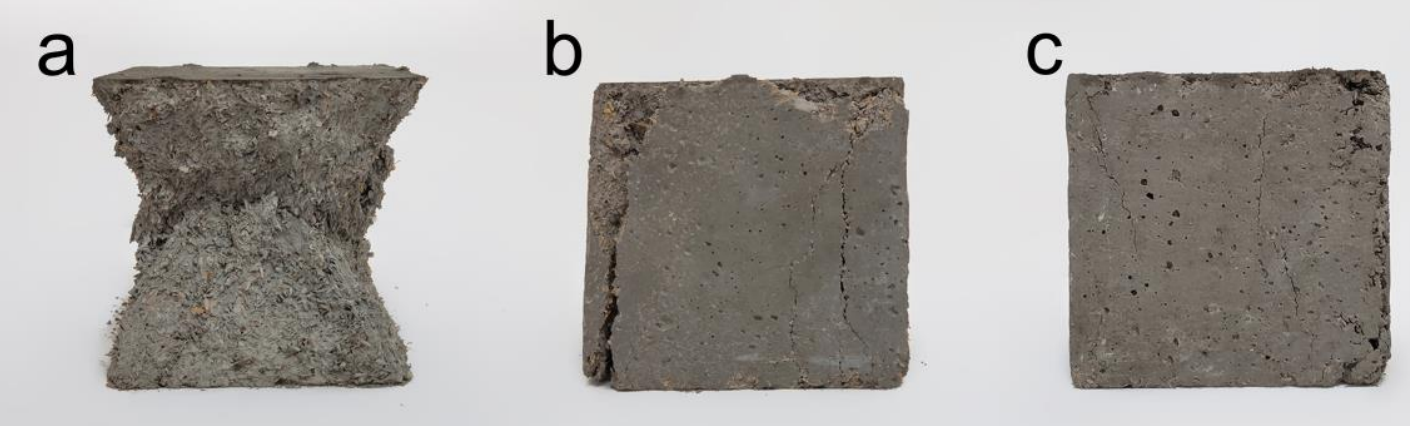

Fig. 6. Failure mode of samples

Figure 6 shows the failure modes of three different pretreated samples. Figure 6a shows the composite containing untreated coffee exocarp, and a brittle fracture occurred after the sample was compressed. Hence, when the amount of compression increases, the sample tends to crack in an oblique direction at first, and then, it is further crushed. Finally it was destroyed in the form of inverted triangle cone. It breaks under a smaller force. Figure $6 \mathrm{~b}$ shows the composite containing water-treated coffee exocarp. After the sample was compressed, cracks began to appear on the upper part of the middle of the sample, and the cracks continued to expand to the upper and lower ends. When the sample reached the ultimate load, fracture occurred, and there was an obvious vertical crack that formed a penetrating crack surface. Figure $6 \mathrm{c}$ shows the composite containing coffee exocarp pretreated with a $4 \% \mathrm{NaOH}$ solution, and this sample was subjected to the greatest force of the three. When this sample was destroyed, it had fewer superficial cracks than the sample pretreated with water. Moreover, the width of each crack was reduced, and only a small number of fine cracks appeared.

Compared with ordinary concrete, biomass fiber cement-based composites have better deformation capacity under compression. This is mainly due to the toughening effect of the fibers and the lack of coarse aggregate in the composites. With the same amount of fibers, the fracture toughness of the composite material containing pretreated coffee exocarp was higher than that of the untreated composite material. This was due to the hemicellulose, lignin, and ash contents being lower in the pretreated coffee exocarp composite materials. In addition, the remaining cellulose, which determines the structure and rigidity of the fibers, resulted in a higher physical bonding strength with the cement base. When the fiber is closely bonded to the cement base, the fiber can provide sufficient bridging stress, and the crack width is inhibited to expand further after cracking. At the same time, the fiber assumed the stress released by the matrix, and it transferred the stress to the surrounding uncracked matrix by interfacial bonding, thus generating new cracks. Finally, a large number of approximately parallel fine cracks appeared on the surface of the sample, which was consistent with the crack image of sample C. 


\section{Microscopic Analysis of Composite Materials}

As shown in Fig. 7, microscopic morphological observations were conducted on the surface of the coffee exocarp and the interface between the cement and coffee exocarp using ESEM. The surface of the coffee exocarp pretreated with water was smooth. In contrast, the surface of the coffee exocarp pretreated with a $4 \% \mathrm{NaOH}$ solution was relatively rough, uneven, and rugged. The reason was the removal of pectin and wax coating the fiber surface, and thus, it contained more abundant pore structures. As shown by the red arrow in Fig. 7c, the pectin and wax of coffee exocarp became the barrier of bonding between the two substrates, and thus, the bonding interface between the coffee exocarp and the cement was distinct. At the red arrow in Fig. 7d, the coffee exocarp was not broken, the inner fine fibers did not fall off, and the surface was intact overall. The cement slurry penetrates the pores of the coffee exocarp, and the two are closely bonded to enhance the overall crack resistance of the composite, resulting in a mechanical interlock effect. Alkali treatment changes the orientation of the biomass material fiber order, forming an amorphous region (Bodur et al. 2016). A rough surface morphology is formed in this region. It also includes more channels to immerse the cement matrix into the fiber, thus increasing the surface area of the fiber participating in the bonding (Ray et al. 2001).

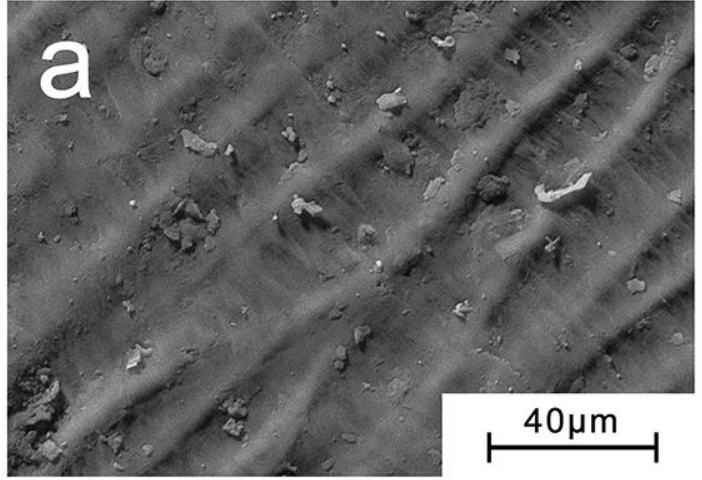

Exocarp water immersion treatment

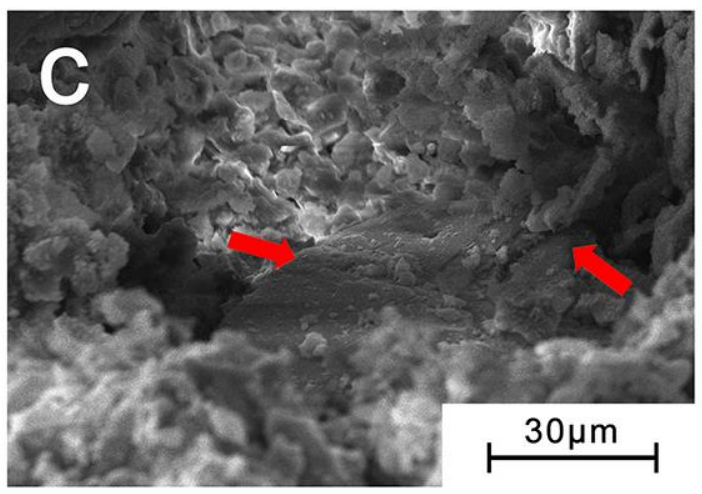

Water treatment interface

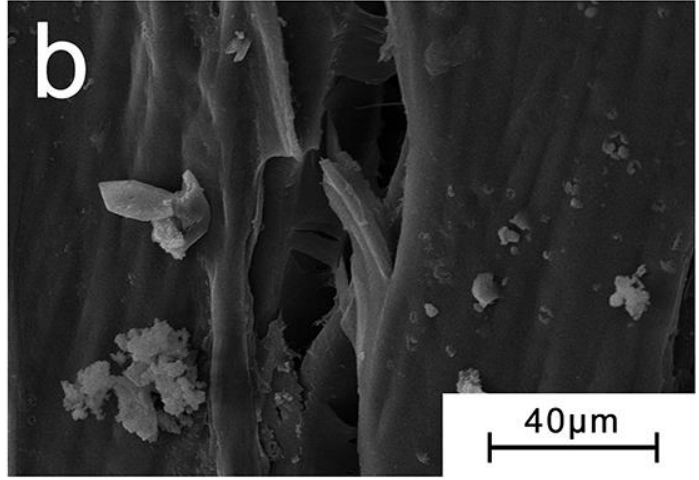

Exocarp $\mathrm{NaOH}$ solution immersion treatment

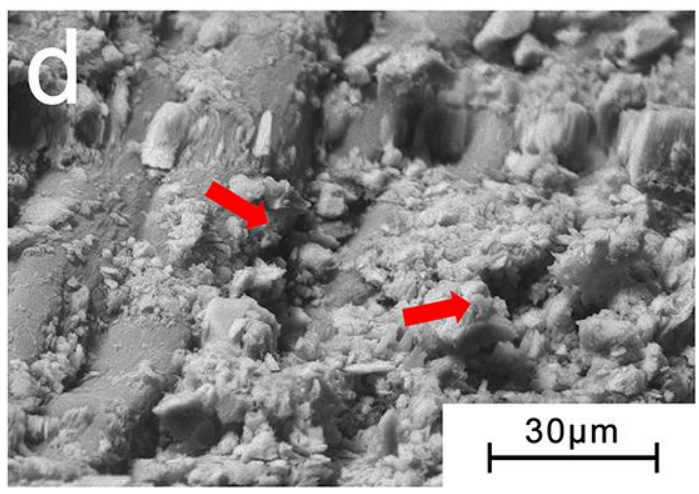

$\mathrm{NaOH}$ solution treatment interface

Fig. 7. The ESEM of the coffee exocarp and composite interface

Figure 8 shows the XRD analysis results of the coffee exocarp composites. Figure 8 a shows the XRD map of the 28 d cured S2 specimen, wherein the primary minerals were $\mathrm{C}_{3} \mathrm{~S}, \mathrm{C}_{2} \mathrm{~S}$, and $\mathrm{Ca}\left(\mathrm{SO}_{4}\right)\left(\mathrm{H}_{2} \mathrm{O}\right)_{2}$. Figure $8 \mathrm{~b}$ shows the XRD map of the $28 \mathrm{~d}$ cured $\mathrm{S} 3$ 
specimen, wherein the main mineral compositions were $\mathrm{C}_{3} \mathrm{~S}$ and $\mathrm{C}_{2} \mathrm{~S}$. It can be seen in Fig. $8 \mathrm{~b}$ that the characteristic absorption peak of $\mathrm{Ca}\left(\mathrm{SO}_{4}\right)\left(\mathrm{H}_{2} \mathrm{O}\right)_{2}$ is reduced to a much lower value, which can be understood by looking at the strong compressive strength of sample $\mathrm{S} 3$ at the same time. The process can be explained as below: the fiber surface becomes rougher and more porous after pretreatment with sodium hydroxide, providing more channels for the hydration of cement mortar and resulting in a high reaction activity. Ions of $\mathrm{SO}_{4}{ }^{2-}$ are released in a large quantity at a high rate by $\mathrm{Ca}\left(\mathrm{SO}_{4}\right)\left(\mathrm{H}_{2} \mathrm{O}\right)_{2}$ at the early stage of hydration, which can quickly react with aluminum minerals and produce ettringite to delay coagulation. As ettringite interconnects into a strong network, cementitious materials can fill in, showing great toughness, and enhance the intensity of composite materials at the early and later stages (Kabir et al. 2012; Savastano et al. 2006).
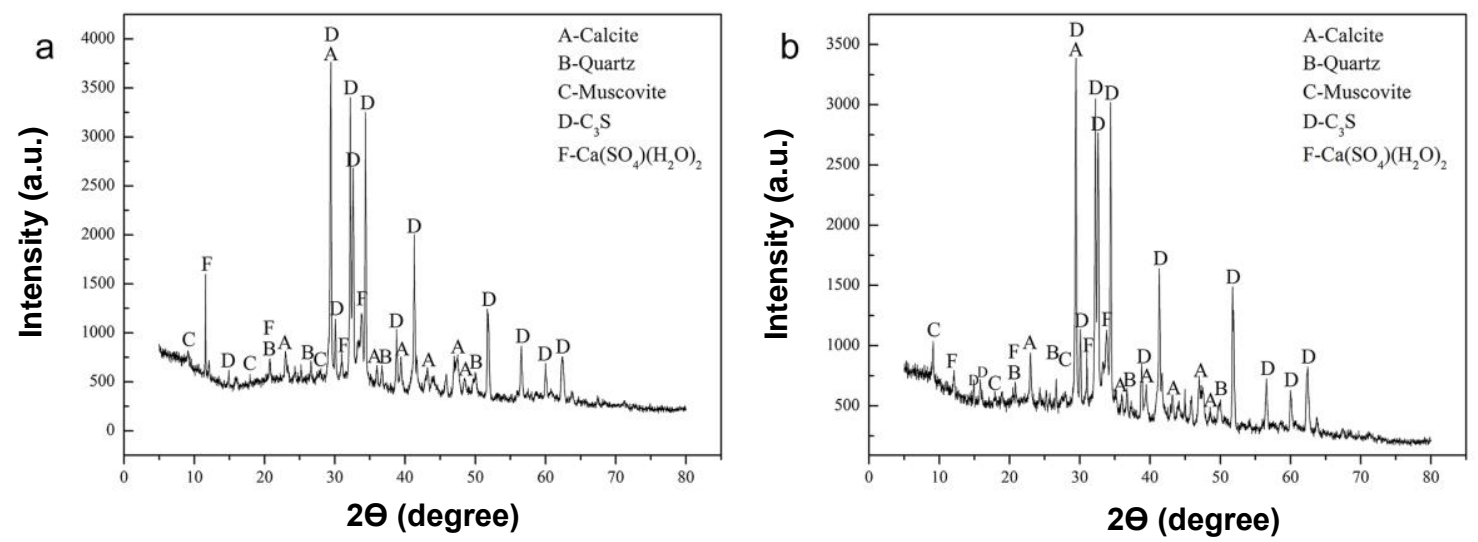

Fig. 8. The XRD of the composites: (a) water treatment; and (b) $4 \% \mathrm{NaOH}$ treatment

\section{Analysis of the Physical Properties of the Composite Materials}

Durability is important for the usability and maintenance of new building materials. To determine whether the material developed in this study could be used as a pavement material in low-load roads, the volume density, water absorption, walking comfort, and porosity of the S1, S2, and S3 samples were studied. The same amount of other three plant fibers was used to replace the coffee exocarp. The plant fibers were pretreated with $4 \%$ $\mathrm{NaOH}$ solution, and the samples were prepared under the same conditions. The physical properties of the different samples were compared after $28 \mathrm{~d}$ of curing (as shown in Table 4).

Table 4. Comparison of the Physical Properties of Coffee Exocarp Composites and Other Plant Material-Based Composites

\begin{tabular}{|c|c|c|c|c|c|c|}
\hline $\begin{array}{c}\text { Test } \\
\text { Number }\end{array}$ & $\begin{array}{c}\text { Sample } \\
\text { Mass } \\
(\mathrm{kg})\end{array}$ & $\begin{array}{c}\text { Compressive } \\
\text { Strength } \\
(\mathrm{MPa})\end{array}$ & $\begin{array}{c}\text { Bulk } \\
\text { Density } \\
\left(\mathrm{g} / \mathrm{cm}^{3}\right)\end{array}$ & $\begin{array}{c}\text { Water } \\
\text { Absorption } \\
(\%)\end{array}$ & $\begin{array}{c}\text { GB } \\
\text { coefficient } \\
(\%)\end{array}$ & $\begin{array}{c}\text { SB } \\
\text { coefficient } \\
(\%)\end{array}$ \\
\hline Control & 8.02 & $26.93^{(0.37)^{*}}$ & $2.37^{(0.08)}$ & $3.54^{(0.14)}$ & 74 & 38 \\
\hline S1 & 4.86 & $8.24^{(0.61)}$ & $1.38^{(0.06)}$ & $6.63^{(0.25)}$ & 19 & 11 \\
\hline S2 & 5.35 & $13.01^{(0.55)}$ & $1.62^{(0.11)}$ & $4.42^{(0.28)}$ & 16 & 8 \\
\hline S3 & 5.07 & $15.72^{(0.48)}$ & $1.51^{(0.09)}$ & $4.31^{(0.18)}$ & 16 & 7 \\
\hline Rice husk & 4.98 & $12.79^{(0.60)}$ & $1.44^{(0.07)}$ & $7.34^{(0.64)}$ & 23 & 12 \\
\hline Straw & 4.16 & $10.84^{(0.83)}$ & $1.19^{(0.16)}$ & $11.47^{(0.89)}$ & 14 & 7 \\
\hline
\end{tabular}

Zhu et al. (2020). "Properties of exocarp composites," BioResources 15(4), 9059-9074. 9070 
As shown in Table 4, the mass of the sample mixed with coffee exocarp was drastically lower than that of the control. The volume density of $\mathrm{S} 3$ was $1.5 \mathrm{~g} / \mathrm{cm}^{3}$ to 1.6 $\mathrm{g} / \mathrm{cm}^{3}$ at $28 \mathrm{~d}$. The mass of S3 was approximately $5.07 \mathrm{~kg} \pm 0.5 \mathrm{~kg}$, which was $63 \%$ of the mass of the control group. The water absorption of S3 was $4.3 \% \pm 0.4 \%$, and its water absorption was close to that of $\mathrm{S} 2$, which was slightly higher than that of the control group. The primary reason was that coffee exocarp, similar to other biomass materials, has a high hydrophilicity, and thus, it slightly increases water absorption. Since the surface of the pretreated plant fibers was destroyed, the internal material was separated out. The pore size of the composite prepared via this method was smaller and denser, and the water absorption of the fiber itself had less influence on the material (Zhang et al. 2010; Zhou et al. 2013). With the extension of the curing time, the water absorption of the sample slightly decreased and tended to be more stable. However, if the composite sample was poured without pretreatment, it led to poor interfacial bonding between the cement base and the plant fiber as well as poor compaction. Therefore, the water absorption and apparent porosity of S1 were higher than the water absorption and apparent porosity of S2 and S3. This sample also had more water to fill the internal pores in a humid environment, and the long-term wet/dry cycle will reduce the durability of the composite.

The elasticity of pavement material is one of the important factors that affects the feeling of feet when people walk. If you walk for a long time on a hard pavement material, poor elasticity can easily cause human fatigue. The GB coefficient represents the shock absorbability, while the SB coefficient represents the repulsive elasticity. The smaller the coefficient values of the two, the less the burden on the body will be. As shown in Table 4, the GB coefficient of biomass cement-based composites is less than 25\%, and the SB coefficient is less than 15\%; therefore, the burden on the body is less. The SB coefficient and GB coefficient of Portland cement pavement are much higher than those of biomass cement-based composite. The composite material was laid on the footpath of a tourist scenic spot and the green path of a residential area, and it can effectively absorb the impact caused by accidentally falling on foot or jogging and reduce the harm to the human body. Its walking comfort is better than that of ordinary Portland cement pavement.

The properties of the coffee exocarp composites were similar to wood composites, which were slightly better than the straw and rice husk cement-based composites. Hence, coffee exocarp composites can replace similar materials in a large number of areas that cultivate coffee. The influence of the biomass moisture content and different pretreatment methods on the mechanical properties and durability of composite materials will be studied in the future to provide the more theoretical evidence for coffee exocarp cement-based composite in the application of pavement material.

\section{CONCLUSIONS}

1. Test design analysis showed that the coffee exocarp content and vacuum extraction time had a significant impact on the compressive strength of the sample. The optimal mixing ratio was $10 \%$ coffee exocarp, $20 \%$ sand content, and a $0.4 \%$ water/cement ratio. The sample was vacuum-extracted for $6 \mathrm{~h}$ and pretreated with a $4 \% \mathrm{NaOH}$ solution for $24 \mathrm{~h}$. The maximum compressive strength of this sample after $28 \mathrm{~d}$ of curing was $15.72 \mathrm{MPa}$. 
2. An alkaline solution pretreatment increased the mass loss of the coffee exocarp and promoted the dissolution of sugars in the fibers. This pretreatment process removed the wax layer from the surface of the coffee exocarp, making the material rougher and improving the interfacial bonding between the coffee exocarp and the cement. The fracture inhibition effect of the pretreatment method is more obvious. When alkalitreated coffee exocarp composites were damaged by the applied force, the cracks were less and thinner. Hence, this pretreatment method was superior to the aqueous solution pretreatment method.

3. After pretreatment, the weight of the composite was $37 \%$ lighter than that of traditional concrete, and the apparent density was $1.5 \mathrm{~g} / \mathrm{cm}^{3}$ to $1.6 \mathrm{~g} / \mathrm{cm}^{3}$. Under the same conditions, the compressive strength and bulk density of the coffee exocarp composites were damaged by the applied force, while the cracks were less and thinner.

4. The golf ball (GB) coefficient and steel ball (SB) coefficient of biomass fiber cementbased composites were significantly lower than those of ordinary Portland cement pavement, with a more comfortable feeling for walking. At the same time, coffee exocarp is a coffee production waste, which is low-cost. The coffee exocarp cementbased composite material is feasible and suitable for low-load pavement, e.g., green roads and pedestrian roads.

\section{ACKNOWLEDGMENTS}

The authors would like to thank the Yunnan Provincial Department of Education (2019Y0146), Applied Basic Research Foundation of Yunnan Province (2014FD032), Guizhou Provincial Highway Bureau Science and Technology Project Fund (2018QLT06) and National Natural Science Foundation of China (No. 51808467) for their financial support.

\section{REFERENCES CITED}

Arulrajah, A., Kua, T.-A., Suksiripattanapong, C., Horpibulsuk, S., and Shen, J. S. (2017). "Compressive strength and microstructural properties of spent coffee grounds-bagasse ash based geopolymers with slag supplements," Journal of Cleaner Production 162, 1491-1501. DOI: 10.1016/j.jclepro.2017.06.171

ASTM C109 (2005). "Standard test method for compressive strength of hydraulic cement mortars(using 2-in. or [50-mm] cube specimens)," ASTM International, West Conshohocken, PA.

ASTM C29 (2009). "Standard test method for bulk density (unit weight) and voids in aggregate," ASTM International, West Conshohocken, PA.

ASTM C33 (2003). "Standard specification for concrete aggregates," ASTM International, West Conshohocken, PA.

Ataie, F. F., Juenger, M. C. G., Taylor-Lange, S. C., and Riding, K. A. (2015). "Comparison of the retarding mechanisms of zinc oxide and sucrose on cement hydration and interactions with supplementary cementitious materials," Cement and Concrete Research 72, 128-136. DOI: 10.1016/j.cemconres.2015.02.023 
Bekalo, S. A., and Reinhardt, H.-W. (2010). "Fibers of coffee husk and hulls for the production of particleboard," Materials and Structures 43(8), 1049-1060. DOI: 10.1617/s11527-009-9565-0

Bodur, M. S., Bakkal, M., and Sonmez, H. E. (2016). "The effects of different chemical treatment methods on the mechanical and thermal properties of textile fiber reinforced polymer composites," Journal of Composite Materials, 50(27), 38173830. DOI: $10.1177 / 0021998315626256$

Coutts, R. S. P. (2005). “A review of Australian research into natural fibre cement composites," Cement and Concrete Composites 27(5), 518-526. DOI: 10.1016/j.cemconcomp.2004.09.003

Fan, M., Ndikontar, M. K., Zhou, X., and Ngamveng, J. N. (2012). "Cement-bonded composites made from tropical woods: Compatibility of wood and cement," Construction and Building Materials 36, 135-140. DOI:

10.1016/j.conbuildmat.2012.04.089

Garci Juenger, M. C., and Jennings, H. M. (2002). "New insights into the effects of sugar on the hydration and microstructure of cement pastes," Cement and Concrete Research, 32(3), 393-399. DOI: 10.1016/S0008-8846(01)00689-5

Kabir, M. M., Wang, H., Lau, K. T., and Cardona, F. (2012). "Chemical treatments on plant-based natural fibre reinforced polymer composites: An overview," Composites Part B: Engineering, Elsevier Ltd, 43(7), 2883-2892. DOI: 10.1016/j.compositesb.2012.04.053

Khorami, M., and Ganjian, E. (2011). "Comparing flexural behaviour of fibre-cement composites reinforced bagasse: Wheat and eucalyptus," Construction and Building Materials 25(9), 3661-3667. DOI: 10.1016/j.conbuildmat.2011.03.052

Qiao, J., Wang, A., and Li, X. (2015). "Preparation and performance of wheat-straw composite board with inorganic adhesive," BioResources 11(1), 103-107. DOI: 10.15376/biores.11.1.819-826

Ray, D., Sarkar, B. K., Rana, A. K., and Bose, N. R. (2001). "Effect of alkali treated jute fibres on composite properties," Bulletin of Materials Science, 24(2), 129-135. DOI: 10.1007/BF02710089

Savastano, H., Turner, A., Mercer, C., and Soboyejo, W. O. (2006). "Mechanical behavior of cement-based materials reinforced with sisal fibers," Journal of Materials Science 41(21), 6938-6948. DOI: 10.1007/s10853-006-0218-1

Savastano, H., Warden, P. G., and Coutts, R. S. P. (2003). "Potential of alternative fibre cements as building materials for developing areas," Cement and Concrete Composites 25(6), 585-592. DOI: 10.1016/S0958-9465(02)00071-9

Song, W., Zhao, F., Yu, X., Wang, C., Wei, W., and Zhang, S. (2015). “Interfacial characterization and optimal preparation of novel bamboo plastic composite engineering materials," BioResources 10(3), 5049-5070. DOI:

10.15376/biores. 10.3.5049-5070

Soroushian, P., Aouadi, F., Chowdhury, H., Nossoni, A., and Sarwar, G. (2004). "Cement-bonded straw board subjected to accelerated processing," Cement and Concrete Composites 26(7), 797-802. DOI: 10.1016/j.cemconcomp.2003.06.001

Teixeira, J. N., Silva, D. W., Vilela, A. P., Savastano, H., de Siqueira Brandão Vaz, L. E. V., and Mendes, R. F. (2020). "Lignocellulosic materials for fiber cement production," Waste and Biomass Valorization 11(5), 2193-2200. DOI: 10.1007/s12649-018-0536-y 
Torkaman, J., Ashori, A., and Momtazi, A. S. (2014). "Using wood fiber waste, rice husk ash, and limestone powder waste as cement replacement materials for lightweight concrete blocks," Construction and Building Materials 50, 432-436. DOI: 10.1016/j.conbuildmat.2013.09.044

Torres, F. G., and Cubillas, M. L. (2005). "Study of the interfacial properties of natural fibre reinforced polyethylene," Polymer Testing 24(6), 694-698. DOI: 10.1016/j.polymertesting.2005.05.004

Wang, W. J., and Wu, C. H. (2013). "Benefits of adding rice straw coke powder to cement mortar and the subsequent reduction of carbon emissions," Construction and Building Materials 47, 616-622. DOI: 10.1016/j.conbuildmat.2013.05.066

Whittle, M., Orofino, T., and Miller, K. (1994). "Technical approach to characterization of perceived comfort of walking surfaces," Gait \& Posture, 2(2), 129-133. DOI: 10.1016/0966-6362(94)90103-1

Xie, X., Gou, G., Wei, X., Zhou, Z., Jiang, M., Xu, X., Wang, Z., and Hui, D. (2016). "Influence of pretreatment of rice straw on hydration of straw fiber filled cement based composites," Construction and Building Materials 113, 449-455. DOI: 10.1016/j.conbuildmat.2016.03.088

Xie, X., Zhou, Z., Jiang, M., Xu, X., Wang, Z., and Hui, D. (2015). “Cellulosic fibers from rice straw and bamboo used as reinforcement of cement-based composites for remarkably improving mechanical properties," Composites Part B: Engineering 78, 153-161. DOI: 10.1016/j.compositesb.2015.03.086

Zhang, X., Zhao, Q., Wang, S., Trejo, R., Lara-Curzio, E., and Du, G. (2010). "Characterizing strength and fracture of wood cell wall through uniaxial microcompression test," Composites Part A: Applied Science and Manufacturing 41(5), 632-638. DOI: 10.1016/j.compositesa.2010.01.010

Zhang, Y., Gu, J., Tan, H., Di, M., Zhu, L., and Weng, X. (2011). "Straw based particleboard bonded with composite adhesives," BioResources 6(1), 464-476. DOI: 10.15376/biores.6.1.464-476

Zhou, X., Ghaffar, S. H., Dong, W., Oladiran, O., and Fan, M. (2013). "Fracture and impact properties of short discrete jute fibre-reinforced cementitious composites," Materials \& Design 49, 35-47. DOI: 10.1016/j.matdes.2013.01.029

Article submitted: August 2, 2020; Peer review completed: September 5, 2020; Revised version received: September 30, 2020; Accepted: October. 11, 2020; Published: October $15,2020$.

DOI: $10.15376 /$ biores.15.4.9059-9074 